\title{
Immunological influences on reproductive neuroendocrinology
}

\author{
GK Barrell \\ Agriculture and Life Sciences Division, PO Box 84, Lincoln University, Lincoln 7647, New Zealand
}

One of the consequences of activation of the immune system, with its associated inflammatory responses and operation of the stress axes, is a generalised inhibition of reproductive function. This can be considered as part of the all-encompassing effects of an activated immune system, included in which is the 'immunological cost' arising from the nutritional demand required to maintain a competent, responsive immune system, and the pathological effects produced by severe immune responses. Elucidation of specific immune-neuroendocrine linkages has largely involved examination of corticosteroid-based mechanisms or use of bacterial endotoxin as a model stimulus and examination of effects on $\mathrm{GnRH}$ and $\mathrm{LH}$ pulsatility, on GnRH and $\mathrm{LH}$ surge processes and on pituitary responsiveness to $\mathrm{GnRH}$, using various sheep models. Although there is good evidence for prostaglandins as common mediators for endotoxin-induced and stress axis-induced impairment of neuroendocrine reproductive processes, both mechanisms appear to have prostaglandinindependent pathways as well. At the anterior pituitary gland level, the type II glucocorticoid receptor appears to mediate corticosteroid effects. Otherwise, the identity of specific cytokines, their sites of action and the cell level mechanisms underlying the inhibition of the reproductive axis at hypothalamic and anterior pituitary levels, especially in sheep, remains largely unresolved.

\section{Introduction}

This review is intended to provide initially a brief perspective of the immune system and its impacts on body systems in general, and on neuroendocrine pathways in particular. Thereafter, the primary objectives are to review recent research activity that has focused on mechanisms of immune stress-associated effects, largely involving corticosteroids, and cytokine-mediated effects on neuroendocrinology of reproduction with particular emphasis on studies with sheep.

\section{The immune system}

What is the immune system?

The immune system can be regarded as a defence mechanism, the impairment of which has tragic consequences, as demonstrated by genetic or acquired (e.g. AIDS) severe immunodefi- 
ciencies. Although it influences the function of most bodily systems, enables tolerance of 'self' and can reject tumours, its genesis is largely based on the need of vertebrates to cope with challenges from pathogenic organisms.

Innate immunity includes the physical epithelial barriers encountered by pathogenic organisms attempting to invade an animal and the antimicrobial factors produced by epithelia, plus macrophages and other cells that have receptors for cell-surface molecules on the organisms. This provides for interactions that may lead to phagocytosis of the invading organisms and/or activation of macrophages causing induction of an inflammatory response, and recruitment of other cell types to the site. Such pathogens may also be recognised by the complement system causing enhancement of their phagocytosis as well as activation of inflammatory responses. Antigen-specific responses are recruited from other cells attracted to the site of infection and through uptake of antigen by dendritic cells that transport antigen to lymphoid tissue where primary immune responses are initiated.

Adaptive immunity includes primary immune responses that occur when antigenic substances interact with antigen-specific lymphocytes, most commonly causing production of specific antibody molecules and proliferation of antigen-specific helper and effector T-lymphocytes. The latter cells can produce killer T cells capable of lysing infected cells. Secondary immune responses involve the formation of immunologic memory during the primary event that produces an enhanced immune response at subsequent exposure to antigen - i.e. a state of immunity and the basis of vaccination. The specificity of the immune response is determined by lymphocytes which makes them central players in the system, but a whole raft of other leukocytes plus specialised epithelial and stromal cells are involved in the immune process by providing the anatomical environment for conducting it as well as secreting chemical factors that regulate migration, growth, and/or gene activation of cells in the immune system. Antibodies are large immunoglobulin molecules that can be expressed on the cell surface of lymphocytes and secreted into the surrounding environment. Another group of chemicals that mediate the functions of cells in the immune system are small proteins referred to as cytokines. Their definition has been discussed by Turnbull and Rivier (1999) who grouped them usefully into eight families, namely: interleukins (e.g. IL-2, IL-3, etc.), tumour necrosis factors (e.g. TNF- $\alpha$, etc.), interferons, chemokines, haematopoietins, colony stimulating factors, neurotrophins, and growth factors. A complication is that many peptides with mediatory functions are common to the immune, nervous and neuroendocrine systems. For example, GnRH, a well established hypothalamic neuropeptide with a central role in reproduction, is also produced by Tlymphocytes and affects laminin receptor expression in lymphocytes (Chen et al. 2002) thus having a potential role as an immunological mediator. This illustrates the difficulty, highlighted in a recent review (Shepherd et al. 2005), of classifying peptides using nomenclature such as 'cytokines' or 'neuropeptides' as well as confounding the linkages between immune and neuroendocrine function. Interestingly, the various signalling chemicals that have evolved within one cytokine molecular family, the class-I helical cytokines, include some members generally regarded as classical peptide hormones, e.g. leptin, growth hormone, prolactin, erythropoietin (Huising et al. 2006).

\section{Immune-nervous interactions}

Involvement of the central nervous system (CNS) in regulation of immune processes at many levels is well established (e.g. Sternberg \& Webster 2003; Shepherd et al. 2005) and the, now classical, arms of the neuroendocrine and neuronal responses to stress, i.e. the hypothalamicpituitary-adrenal (HPA) axis and sympathetic adrenal medulla (SAM) system, are both impor- 
tant in regulation of immune responses. Both divisions of the autonomic nervous system, i.e. sympathetic and parasympathetic, modulate immune function indirectly by their various actions on blood circulation, smooth muscles, secretory glands, etc., as well as directly via receptors on virtually all immune cells, including macrophages and lymphocytes. There are other examples of neural effects on immunological processes (e.g. Shepherd et al. 2005), however, the focus of this review is on the converse interaction; the effects of the immune system on neuroendocrine function, specifically the reproductive neuroendocrine axis.

\section{Modulation of nervous function by immune factors}

Within the CNS immune chemicals such as cytokines act like growth factors affecting neuronal cell death and survival. These cytokines and/or their receptors are synthesised directly by cells of the CNS which include resident glia or immune cells that have invaded the CNS (Sternberg \& Webster 2003). Such immunoregulation is a constitutive function of these cells that is likely to be enhanced under pathological conditions or when the immune system is activated. In contrast, cytokines that reach the CNS from outside this system are likely to act, by definition, in an endocrine manner as classical hormones. For instance some cytokines act like neuropeptides and cause such centrally mediated events as fever, sleep, changes in behaviour, or activation of hormonal stress responses (Sternberg \& Webster 2003). However, the occurrence of such an endocrine role of cytokines within the CNS had remained largely unproven until sufficient quantities of pure recombinant cytokines became available to test these theories directly.

Another issue related to an endocrine role of cytokines in the CNS is that of their access to brain cells. One way in which compounds such as cytokines can surmount the blood-brain barrier is by leaving the circulation at regions in the CNS where the blood-brain barrier does not exist, or the vessels are leaky. Such regions are in the circumventricular organs which include: median eminence, area postrema, subfornical organ, organum vasculosum of the lamina terminalis, and choroid plexus (Sternberg \& Webster 2003). Many of these organs are located close to areas of the CNS that are linked to neuroendocrine regulatory centres, such as the hypothalamus. Access to CNS tissue can be gained also by means of active transport processes across the endothelium of CNS blood vessels (Banks 2001) or, alternatively, cytokines can signal their presence through activation of secondary messengers located at the endothelial cell membranes and achieve their effects on CNS function indirectly (Scammell et al. 1996; Elmquist et al. 1997). Another means of indirect signalling of the CNS by cytokines involves activation of sensory nervous input. For example, paraganglia cells in lymphoid tissue can signal the brain via vagal afferents when there is some change in activity of the lymphoid organs (Goehler et al. 2000).

\section{Impacts of the immune system on body function in general - 'immunological cost'}

Whenever the immune system of an animal is activated there is the possibility that this can be accompanied by major impacts on body function. It is now widely recognised that these impacts largely result from the immune responses themselves. A dramatic example is toxic shock syndrome following infection by streptococcal bacteria (Stevens 1995). A recent example involving an intestinal nematode parasite was provided by Greer et al. (2005). Lambs in the study were treated with an immunosuppressive dose of corticosteroid that was sufficient to allow establishment of a high worm burden. In spite of the greater infection of the immunosuppressed sheep, their live-weight gain and feed conversion efficiency was not affected, showing 
the benefits in terms of nutrients spared from the need to maintain immune responsiveness and also indicating little actual harm caused to the sheep by the parasites per se. As in the case of toxic shock syndrome, most of the detrimental effects of the intestinal parasitism arose from the immune responses to the infective organism, not the organism itself. Collectively, these and similar findings lend support to the concept of an 'immunological cost', that is the metabolic cost of maintaining immunological competence or mounting an immune response (Colditz 2004) with or without the additional burden of pathology arising from tissue damage caused by severe immune responses.

Any change in nutritional status arising from activation of the immune system is likely to alter neuroendocrine function directly via changes in supply of nutrients and by actions of signalling molecules. Such molecules include leptin, which is involved in communicating nutritional status information to the reproductive neuroendocrine axis in sheep (Adam et al. 2003) and cows (Barb \& Kraeling 2004), and grhelin, which is associated with meal-related neuroendocrine signalling in ruminants (Sugino et al. 2004).

\section{Immunostimulation as a stressor}

It is not surprising from evidence of its major impacts on body function that activation of the immune response cascade causes major disturbances of neuroendocrine function. Whether it is by default or by design, as it makes sense to curtail the expense of reproductive function if survival of the individual is threatened, the consequences for the reproductive axis when the immune system is activated are not unexpected. What is not so clear are the details of the mechanisms by which activation of the immune response cascade imposes its effects on the reproductive axis. Immunostimulation is one of the responses to an adverse environmental stress, such as exposure to antigens, and can be considered as being akin to responses such as those caused by thermal stress, malnutrition, psychological stress, physical injury, hypoxia or any of the stressors that activate stress responses in animals. In the current view, many or maybe all of these stressors appear to produce co-ordinated suites of responses mediated by the brain, particularly via the amygdala - the two organs of which form part of the sub cortical limbic system. These organs may be the central processors of the myriad of inputs from various stressors that in turn regulate the major responses of the body to stress. For simplicity these have been allocated into four categories, namely: (1) changes in behaviour, i.e. change of skeletal muscle function; (2) activation of the SAM system; (3) activation of the HPA axis; and (4) activation of immune responses, i.e. immunostimulation. Two of these response categories, 2 - the SAM system and 3 - HPA axis, are well-established as being regulated at various levels within the hypothalamus and there is increasing evidence (Turnbull \& Rivier 1999) that the fourth category - immunostimulation - also undergoes regulatory interaction within the hypothalamus. Presumably, the motor region of the cerebral cortex plays a major part in the behavioural changes - response category 1 (above) - although these are considerably influenced by structures operating below the level of consciousness, such as in the limbic system. Activation of the SAM system causes release of adrenergic hormones which are powerful immunoregulators and activation of the HPA axis causes immuosuppresion via release of glucocorticoids. This means that much of the research on effects of stress on reproduction merges with that involving the immune system.

\section{Corticosteroid-mediated effects}

Studies involving the administration of the bacterial endotoxin, lipopolysaccharide (LPS), a commonly-used model of immune stress in sheep, have demonstrated a concurrent activation 
of the neuroendocrine stress axis (Battaglia et al. 1997; Battaglia et al. 1998; Dadoun et al. 1998; Williams et al. 2001). This may be centrally mediated in the hypothalamus or by direct action of cytokines on the adrenal cortex (Turnbull \& Rivier 1999). To test the hypothesis that cortisol mediates the inhibitory actions of endotoxin on pulsatile $\mathrm{GnRH}$ and $\mathrm{LH}$ secretion in sheep, Debus et al. (2002) working in Professor Fred Karsch's laboratory at The University of Michigan separated the effects of cortisol alone from those of the endotoxin-induced release of cortisol by use of metyrapone, an inhibitor of cortisol synthesis. Their work showed that although cortisol itself inhibited pulsatile GnRH and LH secretion, the marked release of cortisol provoked by administration of LPS was not required for the inhibitory effects of the bacterial endotoxin. In addition, they ruled out the possibility that their results were attributable to progesterone which was also released in response to LPS and was probably of adrenal origin because ovariectomised ewes were used. They concluded that more than one pathway must be responsible for the immune-mediated inhibition of reproductive activity, although one of these involves enhanced secretion of cortisol. Further work in Professor Karsch's laboratory with ovariectomised ewes (Breen \& Karsch 2004) indicated that the site of action of cortisol in these animals is localised to the anterior pituitary gland where it lowered responsiveness to GnRH, rather than by a direct effect on hypothalamic release of $\mathrm{GnRH}$. Their results showed a cortisolinduced suppression of $\mathrm{LH}$ pulse amplitude but no effect on pulse frequency of $\mathrm{LH}$ or $\mathrm{GnRH}$ and no effect on pulse amplitude of GnRH. However, the ovariectomised ewe model provides a very different steroid milieu from that experienced by ovarian intact ewes and eliminates potential effects of cortisol on the ovary that would alter steroid feedback at hypothalamic and pituitary gland levels. Subsequently, studies in the same laboratory have shown that stress-like elevations of plasma cortisol concentration suppressed pulsatility of LH secretion in follicularphase ovarian intact ewes (Breen et al. 2005a), interfered with the preovulatory rise in plasma oestradiol concentration and blocked or delayed the preovulatory $\mathrm{LH}$ and FSH surges. The observation that LH pulsatility was suppressed in these intact ewes implicates the hypothalamus as a central component of this effect of cortisol. This is in clear contrast to the earlier finding with ovariectomised ewes in which there was no evidence of an effect at the hypothalamic level (Breen \& Karsch 2004), suggesting a lack of sensitivity to the pulse frequency suppressing effect of cortisol in such animals. Concern that this lack of effect in ovariectomised ewes might have arisen from inadequate duration of exposure to elevated cortisol levels has been ruled out by showing that 28 hours of cortisol treatment was also without effect (Oakley et al. 2006). These contrasting results indicate that central responsiveness to the effects of cortisol is dependent on the presence of ovary-derived factors (e.g. ovarian steroids). However, in the case of the pre-ovulatory surge of $\mathrm{LH}$, the ability of elevated cortisol concentrations to block or delay this process is not affected by the ovarian steroid milieu, as shown by Wagenmaker et al. (2005). Recently, Breen and Karsch (2006) demonstrated that the cortisolinduced suppression of $\mathrm{LH}$ pulse amplitude in ovariectomised ewes was not influenced by season of the year, which contrasts starkly with the well-known effects of season on feedback by ovarian steroids.

In support of actions of cortisol at the level of the ovine hypothalamus is the evidence for presence of the type II glucocorticoid receptor in neurons of the preoptic area and arcuate nucleus (Dufourny \& Skinner 2002). This receptor is co-expressed with the progesterone receptor and the estrogen $\alpha$-receptor (ER- $\alpha$ ) (Dufourny \& Skinner 2002). By use of RU486, an antagonist, and dexamethasone, a specific agonist, Professor Karsch and his co-workers (Breen et al. 2004b; Case et al. 2005) have provided good evidence that the type II glucocorticoid receptor also mediates the cortisol-induced suppression of pituitary responsiveness in the ovariectomised ewe, i.e. a pituitary-level site of action for this receptor. 
It is clear from these studies that both components of the hypothalamic-pituitary axis are involved in mediation of stress effects on reproduction. In the anterior pituitary gland of castrated male sheep, cortisol interfered with oestrogen-stimulated increase in expression of GnRH receptor (Adams et al. 1999), probably via classical nuclear glucocorticoid receptors and the resulting activation of transcription processes, as shown by Maya-Nunez et al. (2003) in rat pituitocyte cultures. However, Professor Karsch and his colleagues recently reported a study of ovariectomised ewes where there was no effect of cortisol on pituitary content of GnRH receptor (Breen et al. 2005b). This result appears to conflict with the findings of Adams et al. (1999) and leaves this involvement of GnRH receptors at the pituitary level unresolved. Also, when the pituitary gland was disconnected from hypothalamic regulation by surgical transection, $\mathrm{GnRH}$-stimulated output of LH secretion was suppressed by various stressors, showing that there is a pituitary-only component involved in the inhibitory effects of stress (Stackpole et al. 2003). However, because the HPA axis was disrupted, cortisol would not have been involved in mediation of this effect of stress (Stackpole et al. 2003).

As well as the moderately confusing picture provided by some of the work reviewed above, there has to be caution about interpretation of the role and actions of corticosteroids in the responses to stress, especially in relation to immunity and inflammation. The co-involvement of cortisol in the inhibition of reproductive function induced by bacterial endotoxin, as discussed above, may appear to be at odds with the recognised immunosuppressive/anti-inflammatory roles of glucocorticoids. Also, these corticosteroids must participate in the negative feedback regulation of the HPA axis, thus inhibiting their own secretion. The complexity of involvement of these steroids in the responses to stress was comprehensively reviewed by Sapolsky et al. (2000). Since then, the research group led by Masugi Nishihara at the University of Tokyo has shown that glucocorticoids counteracted the TNF- $\alpha$-induced inhibition of LH pulsatility (Matsuwaki et al. 2003) and the LH surge (Matsuwaki et al. 2004) in rats. Also they showed that adrenalectomy actually enhanced the inhibition of LH pulsatility in ovariectomised rats exposed to a variety of stressors including infection (Matsuwaki et al. 2006). These workers have implicated prostaglandins as the mediators of stress-induced suppression of $\mathrm{LH}$ pulsatility by using combinations of adrenalectomy, corticosterone and indomethacin (a cyclo-oxygenase inhibitor) on ovariectomised rats subjected to hypoglycaemic (2-deoxy glucose) or infectious (LPS) stress (Matsuwaki et al. 2006). A similar role for prostaglandins in sheep had been provided earlier (Harris et al. 2000, see below). However, as well as the blockade by corticosterone of the stress-induced inhibition of LH pulsatility (mainly reduced pulse amplitude), this steroid counteracted the stress-induced elevation of cyclo-oxygenase immunoreactivity in the brain (Matsuwaki et al. 2006) showing a direct inhibitory effect of corticosteroids on the involvement of prostaglandins, by reducing their synthesis. This and related work with rats has lead to the concept that prostaglandins may be common mediators of stress-induced inhibition of the reproductive axis (Maeda \& Tsukamura 2006). Also these authors contend that the output of glucocorticoids resulting from an activated HPA axis initially has a protective role by suppressing prostaglandin synthesis and, hence, helping to maintain reproductive function in spite of the underlying stressor activity (Maeda \& Tsukamura 2006). This concept of a reproductive support role for glucocorticoids runs counter to their generally reproduction-inhibitory effects, such as those reported in the sheep studies described above. The roles of glucocorticoids are complex and their actions in response to stress can fall into permissive, stimulatory or suppressive categories, depending on the physiological endpoint in question (Sapolsky et al. 2000). The protective role of glucocorticoids during the early phase of the stress response, as described by Maeda \& Tsukamura (2006, above), seems to belong to the suppressive category of response. 


\section{Cytokine-mediated effects}

As mentioned above, cytokines that are released into the circulation following stimulation of cells involved in the immune response have endocrine roles in the CNS and anterior pituitary gland, some of which are directed at components of the $\mathrm{GnRH}$ and gonadotrophin regulatory processes. In contrast, cytokine involvement in regulation of the selection and migration of GnRH neurons during embryonic and early fetal development is most likely to be mediated by locally derived cytokines. Previously, evidence for presence of cytokines and their receptors in the brain and anterior pituitary gland has been reviewed by Sternberg (1997), Benveniste (1998) and Turnbull \& Rivier (1999). The occurrence of receptors for one cytokine, fibroblast growth factor (FGF), in regions of the brain involved in regulation of reproduction has been confirmed by Gill et al. (2004; 2006) using immuncytochemistry. They showed the presence of FGF receptors in developing GnRH neurons of mice and the emergence of these cells to be blocked by FGF receptor antagonists. In addition they reported a stimulatory effect of FGF on neurite outgrowth and branching. Functioning of cranial neurons can also be affected by transcriptional actions of oestrogens operating via classical oestrogen receptors (ER). However, Herbison and his colleagues, using ER-knockout mice, showed that there are rapid negative feedback effects of oestrogens mediated by membrane-level, non-genomic mechanisms (Abraham et al. 2004). Recently it has been shown in sheep that acute suppression of LH secretion by oestradiol or an oestradiol conjugate operates via such a non-genomic mechanism (ArreguinArevalo \& Nett 2006). In the hypothalamus, membrane-level signalling in the negative feedback pathway to $\mathrm{GnRH}$ neurons involves a G protein-coupled receptor (GPR54) for which major ligands are the KiSS-1 peptins (de Roux et al. 2003; Seminara et al. 2003; Dungan et al. 2006). These peptins and their receptor (GPR54) appear to be involved in both inhibitory and stimulatory feedback effects of gonadal steroids in the hypothalamus (Smith et al. 2005) and it has been speculated that KiSS-1 neurons may provide the link between steroidal feedback signals and $\mathrm{GnRH}$ neurons that lack ER- $\alpha$ (Tena-Sempere 2005). It is possible that inflammatory peptides such as cytokines interact with ER both at classical genomic sites and with G proteincoupled receptors at the non-genomic, membrane-level sites. As an example of the former, IL$1 B$ activation of transcription, presumably via the transcription factor NF-kB, is antagonised by oestradiol via ER action at this promoter site (Tyree et al. 2002).

Downstream from the hypothalamus, gonadotropes and folliculostellate cells of the anterior pituitary gland are also implicated as targets for cytokine action (Turnbull \& Rivier 1999). For instance, the pro-inflammatory cytokines, TNF and IL-1, altered the phosphorylation status of a gap junction membrane channel protein (GJA1) in cultured rat folliculostellate cells (Fortin et al. 2006) indicating possible modulation of cell-to-cell communication and, thus, of growth and function of these cells. This affects the growth and secretion of hormones by endocrine cells of the anterior pituitary gland and is just one example of cytokine-pituitary interactions.

As mentioned earlier, one of the components of innate immunity is activation of an inflammatory response. This is generally mediated by the so-called pro-inflammatory cytokines, primarily IL-1, IL-6, II-8 and TNF $\alpha$, and is defined by induction of vasodilation and increased vascular permeability. Probably, it is at the endothelial cell level in organs such as the brain where these cytokines initiate phospholipase activity, thus causing disruption of cell membrane integrity and release of arachidonic acid - a precursor for prostaglandin synthesis by the cyclo-oxygenase pathway, or of leukotrienes by the lipoxygenase pathway. Harris et al. (2000) showed that blockade of prostaglandin synthesis in sheep by use of the cyclo-oxygenase inhibitor, flurbiprofen, prevented endotoxin-induced fever and suppression of $\mathrm{LH}$ secretion, thereby implicating prostaglandins as the possible central mediators of the disturbances in hypothalamo- 
hypophyseal-ovarian function following such inflammatory challenge. The various studies using sheep to investigate the different levels within the reproductive neuroendocrine axis where endotoxin achieves such disruption has been comprehensively reviewed (Karsch \& Battaglia 2002). These authors argued that the advantage of their sheep model over previously reported studies was the large size of the animal which made frequent blood sampling possible, thus enabling high resolution studies of hormonal dynamics. Because of this they were able to dissociate effects of endotoxin at hypothalamic, pituitary and ovarian levels and at various phases of the ovarian cycle (Karsch \& Battaglia 2002). This work has shown that endotoxin interferes with the reproductive neuroendocrine axis at both hypothalamic and pituitary levels. Endotoxin inhibits both pulsatile GnRH secretion and pituitary responsiveness to GnRH (Battaglia et al. 1997; Williams et al. 2001). The effects of endotoxin on LH pulsatility are acute, occurring within one hour (Battaglia et al. 1997; Harris etal 2000; Williams etal. 2001), whereas its effects on the oestrogen-induced LH surge process appear to be installed some 10 to 20 hours before the surge would be expected to occur (Battaglia et al. 1999). Further work (Breen et al. 2004a) showed that the inhibitory effect of endotoxin on the oestradiol-induced surge of $\mathrm{LH}$ in the ewe operated at the level of the hypothalamus by causing blockade of the GnRH surge. Administration of the cyclo-oxygenase inhibitor flurbiprofen did not interfere with this blockade of the $\mathrm{LH}$ surge nor with the inhibition of $\mathrm{LH}$ secretion prior to the surge, although it did prevent fever. This means that, in spite of the dampening effect of endotoxin on pituitary responsiveness to $\mathrm{GnRH}$ mentioned above, endotoxininduced inhibition of the LH surge in ovariectomised ewes is due to inhibition of the GnRH surge mechanism in the hypothalamus. Also, the finding that inhibition of prostaglandin synthesis by flurbiprofen did not overcome the effects of endotoxin on the LH surge in sheep is interesting as it differs from endotoxin inhibition of $\mathrm{GnRH}$ and $\mathrm{LH}$ pulsatility which were blocked by flurbiprofen (Harris etal. 2000). In both studies endotoxin-induced fever was blocked by flurbiprofen, showing that fever and the effect of endotoxin on pulsatility may be mediated by prostaglandins. However, the study by Breen et al. (2004a) indicates the existence of a separate prostaglandin-independent pathway that mediates the effects of endotoxin on the surge process. These various findings could be resolved simply as follows: endotoxin inhibits the GnRH pulse mechanism in the hypothalamus via a prostaglandin mediated pathway and inhibits the surge process, also at a central level, by a prostaglandin-independent pathway. However, the authors mentioned they had gathered initial evidence that the pulse inhibitory mechanism may also not require a prostaglandin-mediated pathway. Nevertheless, because of the differences in latency between endotoxin effects on pulse and surge mechanisms, the authors inferred that the neuroendocrine processes which mediate the endotoxin-induced effects on GnRH pulsing are "separable and fundamentally different" from those mediating the effects on GnRH surges (Breen et al. 2004a). These differential effects of endotoxin had been discussed earlier by Karsch \& Battaglia (2002). Endotoxin-induced blockade of the GnRH surge process at a central level does not rule out existence of a similar effect on the LH surge at the pituitary level, especially as an inhibitory effect on pituitary responsiveness to GnRH has been demonstrated (Williams et al. 2001). However, evidence that the LH surge was of normal amplitude in ewes in which the endotoxin treatment unexplainably failed to block the GnRH surge (Breen et al. 2004a) strongly rules out this possibility, unless the quantity of GnRH secreted was so great that it masked any pituitary-level deficiency.

Existence of prostaglandin-independent pathways in the mediation of endotoxin effects on neuroendocrine events does not overshadow the common role of prostaglandins in stress-induced activation of the HPA axis (described above) and immunostimulation processes, but it does indicate levels of complexity in the regulatory mechanisms that await further resolution. It is not clear whether other central mediators of inhibitory actions on gonadotrophin secretion such as the endogenous opioids and corticotrophin-releasing hormone are released directly in response to endotoxin or via prostaglandin-dependent pathways, nor to what extent cytokines 
released by endotoxin-activated immune cells exert direct endocrine influences in the hypothalamus and anterior pituitary gland. There is evidence that endotoxin does cause release of cytokines in sheep. Intravenous administration of endotoxin to sheep elevated circulating levels of TNF (Coleman et al. 1993; Perkowski et al. 1996; Harris et al. 2000) and increased expression of IL-1ß mRNA in the choroid plexus (Vellucci et al. 1996). However, the role of cytokines at the pituitary gland level is complicated by in vitro studies of cultured ovine pituitary cells that have actually shown an increase in accumulation of LH in the media on administration of either endotoxin (Coleman et al. 1993) or the pro-inflammatory cytokines, IL$1 \alpha$ and IL-1 $\beta$ (Braden et al. 1998). Also, the possible influence of ovarian steroids on production of cytokines or on central responsiveness to immunostimulation provides another level of complexity that is largely unresolved at present.

Virtually all the direct evidence for an inhibitory role of pro-inflammatory cytokines at the central level of regulation of reproduction has been obtained from rats, largely by intracerebroventricular administrations (reviewed by Kalra et al. 1998). A general analysis of cytokine signalling in the brain has been provided by Turnbull \& Rivier (1999) and more recently the receptor-level mechanisms of pro-inflammatory cytokine action in the brain were reviewed by Turrin \& Rivest (2004). The latter concluded that pro-inflammatory cytokines can act on endothelial cells forming the blood-brain barrier and at circumventricular organs to cause release of prostaglandin E-2 (Turrin \& Rivest 2004). Another signalling pathway in the brain involves binding of cytokines to endothelial cells with activation of nitric oxide synthase and production of nitric oxide as the secondary messenger (Wong et al. 1996; Scammell et al. 1996). Both the prostaglandin-mediated and the nitric oxide-mediated mechanisms are important in induction of various brain-level responses from peripherally derived cytokines (Sternberg \& Webster 2003).

Fever is one aspect of the immune response that, in the case of endotoxin administration, is mediated centrally by prostaglandins and which may have direct effects on the reproductive axis. Low dose delivery of LPS (40 ng/ $\mathrm{kg}$ ) induced fever and elevated circulating cortisol levels in sheep (Williams et al. 2001). However, this dose appeared to be near the threshold for effects on GnRH pulsatility because suppression of GnRH pulsing occurred in only a few of the treated ewes and only 10 out of 16 ewes had disrupted LH pulsing. This occurrence of fever without complete disruption of LH pulsing is consistent with an earlier finding (Schillo et al. 1990) that elevated body temperature did not alter LH pulsing in ewes. However, the latter authors reported a reduction in mean plasma $\mathrm{LH}$ concentration that leaves the question of direct effects of elevated body temperature on $\mathrm{LH}$ secretion unresolved. Further work conducted both in Professor Karsch's laboratory in Michigan and at Lincoln University, New Zealand has attempted to determine whether the endotoxin-induced inhibition of LH pulsing is attributable to the elevation of body temperature per se by using cyclo-oxygenase inhibitors to block endotoxin effects in ewes exposed to environmental temperatures that raised their body temperature to values equivalent of endotoxin-induced fever. The results (unpublished) give moderate support for some influence of elevated body temperature per se on inhibition of LH pulsatility, which provides further evidence for a prostaglandin-independent pathway for suppression of the reproductive neuroendocrine axis.

\section{Overview}

It is well accepted that immune/inflammatory stress and activation of HPA axis inhibit the reproductive neuroendocrine axis and previous reviews of this topic (e.g. Karsch \& Battaglia 2002) have shown these disruptive effects acting at several regulatory processes in this axis. In 
the past three to four years there has been further resolution of these pathways, giving insight into separate avenues for direct cytokine actions at central levels and for activation of the HPA axis, with the central disruption mediated by cortisol. Also, there is a clearer view of the involvement of ovarian steroids in these events, as revealed by comparison between studies using ovariectomised and ovarian intact ewes. There are many aspects of brain function in relation to regulation of reproduction in mammals that remain shrouded in mystery. These include changes associated with puberty, seasonality, nutrition, immunostimulation and other forms of stress, and aging. It is almost certain that the mechanisms of some of these changes in brain function will be linked to each other and the continued resolution of regulatory mechanisms for any one of these will unravel and help to explain others. This argument should justify continuation of the stepwise approach to resolving individual pathways that has been demonstrated by the studies reviewed above.

\section{Conclusions}

It is clear that the multiplicity of pathways by which immune-neuroendocrine interactions impinge on the reproductive axis is far from resolved and there is much further investigation required to identify the specific sites, cells and cellular mechanisms that are involved. There is some uncertainty about the specific involvement of ovarian steroids in these processes. However, it seems clear that discrepancies which have arisen between results from studies using ovarian intact ewes and those involving ovariectomised ewes or steroid-replaced ovariectomised ewe models indicate an important role of ovarian steroids in the mechanisms that mediate the effects of stress-activated pathways. Ovarian steroids appear to enhance sensitivity of these pathways, which means that the presence of ovaries is required in any conceptual model of these processes. The ovary can thus be regarded as an essential component of the immune stress-reproductive neuroendocrine axis, i.e. its secretory products are involved in the central mediation of events as well as it being a target endorgan of the female reproductive system. Fig.1 provides a schema based on earlier models (e.g. see Karsch \& Battaglia 2002) that incorporates linkages revealed by recent studies, primarily from those using sheep as experimental animals.

Activation of an immune response, as commonly modelled by administration of bacterial endotoxin, causes the release of pro-inflammatory cytokines as well as activation of the HPA axis with consequent release of corticosteroids. These humoral factors activate endothelial cells within CNS blood vessels or stimulate CNS neurons and anterior pituitary cells directly, leading to suppression of the GnRH pulse generating and surge mechanisms in the hypothalamus and/or inhibiting anterior pituitary responsiveness to $\mathrm{GnRH}$. There is evidence for both prostaglandin mediation and prostaglandin-independent mediation of these processes and for involvement of the type II glucocorticoid receptor in the corticosteroid-mediated events. With respect to ruminant reproduction, it is noteworthy that virtually all of the recent studies are based on sheep as the animal model and much of the sheep work has emanated from a single laboratory.

\section{Acknowledgement}

I am indebted to Professor Fred Karsch of the University of Michigan for providing me with over 15 years of collaborative interaction including many enjoyable months working in his laboratory. He has been instrumental in fostering my involvement in the neuroendocrinology of reproduction in ruminant animals and he introduced me to the role of the immune system in these processes. 
immunostimulation

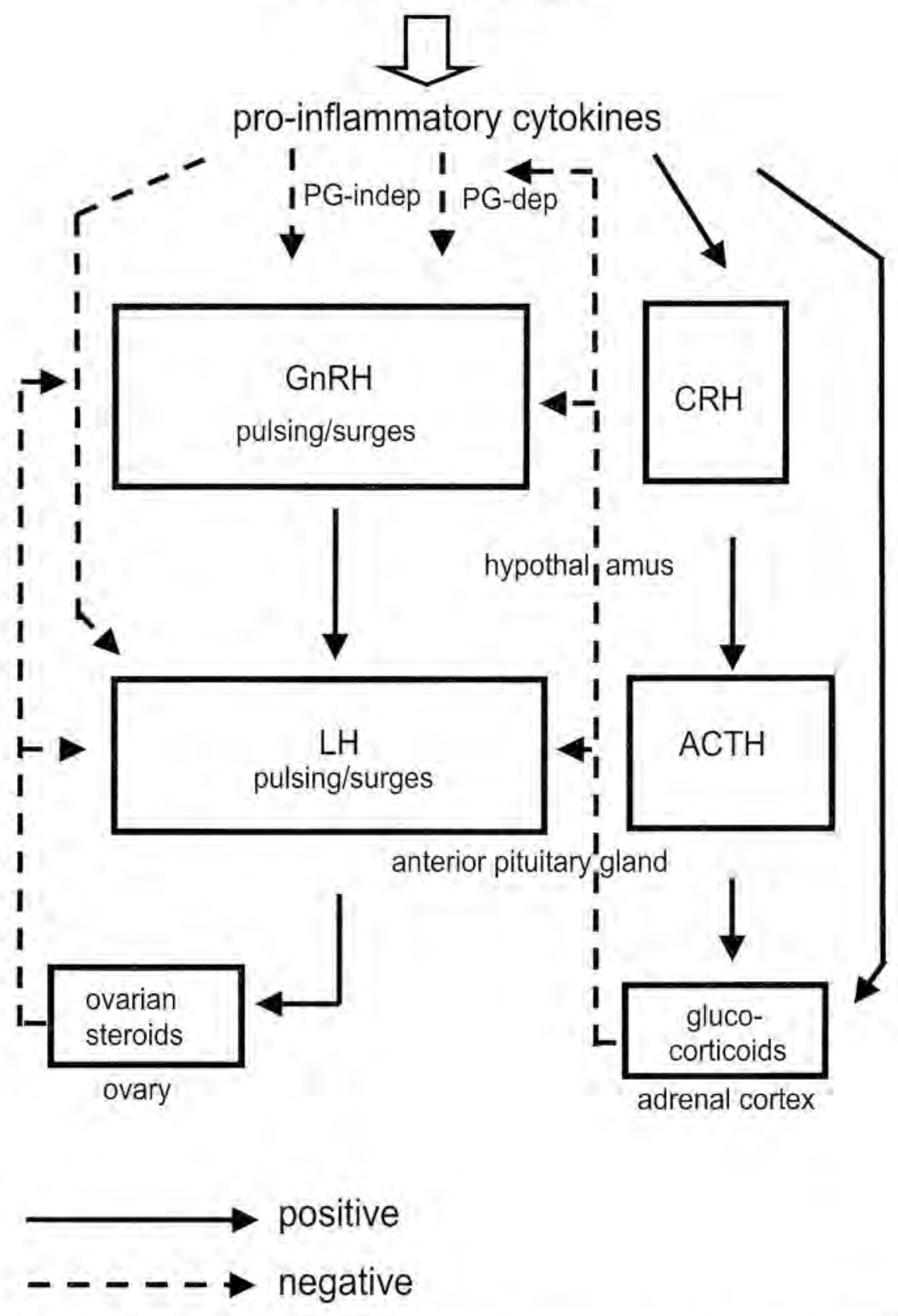

Fig 1. Pathways of linkages between pro-inflammatory cytokines released during immunostimulation and their disruptive effects on the reproductive neuroendocrine axis. Solid arrows represent stimulation, dashed arrows represent inhibition.

N.B. $P G$-indep $=$ prostaglandin-independent, $P G-d e p=$ prostaglandin-dependent 


\section{References}

Abraham IM, Todman MG, Korach KS \& Herbison AE 2004 Crítical in vivo roles for classical estrogen receptors in rapid estrogen actions on intracellular signalling in mouse brain. Endocrinology 1453055 3061.

Adam CL, Archer ZA \& Miller DW 2003 Leplin actions on the reproductive neuroendocrine axis in sheep. Reproduction Supplement 61 283-297.

Adams TE, Sakurai H \& Adams BM 1999 Effect of stresslike concentrations of cortisol on estradiol-dependent expression of gonadotropin-releasing hormone receptor in orchidectomized sheep. Biology of Reproduction 60 164-168.

Arreguin-Arevalo 1A \& Nett TM 2006 A nongenomic action of estradiol as the mechanism underlying the acute suppression of secretion of luteinizing hormone in ovariectomized ewes. Biology of Reproduction 74 202-208.

Banks WA 2001 Cytokines, CVOs, and the blood-brain barrier. In Psychaimmunology, pp. 483-497. Eds R Ader, D Felten \& $N$ Cohen San Diego: Academic Press.

Barb CR \& Kraeling RR 2004 Role of leplin in the regulation of gonadotropin secretion in farm animals. Animal Reproduction Science 82-83 155-167.

Battaglia DF, Bowen IM, Krasa HB, Thrun LA, Viguié C \& Karsch FJ 1997 Endotoxin inhibits the reproductive neuroendocrine axis while stimulating adrenal steroids: a simultaneous view from the hypophyseal porlal and peripheral blood. Endocrinology $1384273-4281$.

Battaglia DF, Brown ME, Krasa HB, Thrun LA, Viguié C \& Karsch FJ 1998 Systemic challenge with endotoxin stimulates cortictropin-releasing hormone and arginine vasopressin secretion into hypophyseal portal blood: coincidence with gonadotropin-releasing hormone suppression. Endocrinology $1394175-$ 4181.

Battaglia DF, Beaver AB, Harris TG, Tanhehco E, Viguié C \& Karsch F) 1999 Endotoxin disrupls the estradiol-induced luteinizing hormone surge: interference with estradiol signal reading, not surge release. Endocrinology 140 2471-2479.

Benveniste EN 1998 Cytokine actions in the central nervous system. Cytokine Growth lactor Reviews 9 259-175.

Braden ID, Fry C \& Sartin IL 1998 Effects of interleukins on secretion of luteinizing hormone from ovine piluilary cells. American Journal of Veterinary Research 59 1488-1493.

Breen KM \& Karsch FJ 2004 Does cortisol inhibil pulsalite luteinizing hormone secretion at the hypothalamic or pituitary level? Endocrinology 145692 698.

Breen KM \& Karsch FJ 2006 Does season alter responsiveness of the reproductive neuroendocrine axis to the suppressive actions of cortisol in ovariectomized ewes? Biology of Reproduction 47 41-45.
Breen KM, Billings HJ, Debus N \& Karsch FI 2004a Endotoxin inhibits the surge secretion of gonadotropin-releasing hormone vía a prostaglandin-independent pathway. Endocrinology $145221-227$.

Breen KM, Stackpole CA, Clarke IJ, Pytiak AV, Tilbrook A), Wagenmaker ER, Young EA \& Karsch F) 2004 b Does the type II glucocorlicosteroid receptor mediate cortisol-induced suppression in pituitary responsiveness to gonadotropin-releasing hormone? Endocrinology $1452739-2746$.

Breen KM, Billings $\mathrm{HJ}$, Wagenmaker ER, Wessinger EW \& Karsch FJ 2005a Endocrine basis for disruplive effects of corlisol on preovulatory events. Endocrinology $1462107-2115$.

Breen KM, Oakley AE, Wagenmaker ER, Rispoli LA, Nett TM \& Karsch FJ 2005b Rapid action of corlisol to suppress pituitary responsiveness to $\mathrm{GnRH}$ occurs independent of decreased $\mathrm{GnRH}$ receptor. $\mathrm{Bi}$ ology of Reproduction, Special Issue for $38^{\text {it }}$ Annual Meeting of the Society for the Study of Reproduction 112 (abstract 137).

Case LC, Breen KM, Wagenmaker ER, Young EA \& Karsch FJ 2005 Does a type II glucocorticoid receptor agonist inhibit pituitary responsiveness to $\mathrm{GnRH}$ ? Biology of Reproduction, Special Issue for $38^{\text {th }}$ Annual Meeting of the Society for the Study of Reproduction 224 (abstract W648).

Chen A, Ganor Y, Rahimipour S, Ben-Aroya N, Koch Y \& Levite M 2002 The neuropeptides GnRH-II and GnRH-I are produced by human T cells and trigger laminin receptor gene expression, adhesion, chemotaxis and homing to specific organs. Nature Medicine 8 1421-1426.

Colditz IG 2004 Some mechanisms regulating nutrient utilisation in livestock during immune aclivation: an overview. Australian journal of Experimental Agriculture 44 453-457.

Coleman ES, Elsasser TH, Kemppainen RJ, Coleman DA \& Sartin JL 1993 Effect of endotoxin on pituilary hormone secretion in sheep. Neuroendocrinology 58 111-122.

Dadoun F, Guillaume V, Sauze N, Farisse I, Velut JG, Orsoni JC, Gaillard R \& Oliver C 1998 Effect of endotoxin on the hypothalamic-pituitary-adrenal axis in sheep. European Journal of Endocrinology 138 1931-197.

Debus N, Breen KM, Barrell GK, Billings HJ, Brown M, Young EA, Karsch FJ 2002 Does cortisol mediate endoloxin-induced inhibition of pulsatile luteinizing hormone and gonadotropin-releasing hormone secretion? Endocrinalogy 143 3748-58.

de Roux N, Genin E, Carel JC, Matsuda F, Chaussain IL \& Milgrom E 2003. Hypogonadotropic hypogonadism due to loss of function of the KiSS1-derived peptide receptor GPR54. Proceedings of the $\mathrm{Na-}$ tional Academy of Science, U.S.A. 100 10972-10976.

Dufournay L \& Skinner DC 2002 Progesterone receptor, estrogen receptor a, and the type II glucocorti- 
coid receptor are coexpressed in the same neurons of the pre optic area and arcuate nucleus: a triple immunolabeling study. Biology of Reproduction 67 1605-1612.

Dungan HM, Clifton DK \& Steiner RA 2006 Minireview: kisspeptin neurons as central processors in the regulation of gonadotropin-releasing hormone secretion. Endocrinology $1471154-1158$.

Elmquist JK, Scammell TE \& Saper CB 1997 Mechanisms of CNS response to systemic immune challenge: the febrile response. Trends in Neuroscience 20 565-570.

Fortin M-E, Pelletier R-M, Meilleur M-A \& Vitale MI 2006 Modulation of GIA1 turnover and intercellular communication by pro-inflammatory cylokines in the anterior pituitary folticulostellate cell line TtT/GF. Biology of Reproduction 74 1-12.

Goehler LE, Gaykema RPA, Hansen MK, Anderson K, Maier SF \& Watkins LR 2000 Vagal immune-10brain communication: a visceral chemosensory pathway. Autonomic Neuróscience 85 49-59.

Gill IC, Moenter SM \& Tsai P-S 2004 Developmental regulation of gonadotropin-releasing hormone neurons by fibroblast growth factor signalling. Endocinology 145 3830-3839.

Gill JC \& Tsai P-S 2006 Expression of a dominant negalive FGF receptor in developing GnRH1 neurons disrupts axon growth and targeting in the median eminence. Biology of Reproduction 74 463-472.

Greer AW, Stankiewicz M, Jay NP, McAnulty RW \& Sykes AR 2005 The effect of concurrent corticosteroid induced immuno-suppression and infection with the inteslinal parasite Trichostrongylus colubriformis on food intake and utilization in both immunologically natve and competent sheep. Animal Science 80 89-99.

Harris TG, Battaglia DF, Brown ME, Brown MB, Carlson NE, Viguié C, Williams CY \& Karsch FJ 2000 Proslaglandins mediate the endotoxin-induced suppression of pulsatile gonadotropin-releasing hormone and luteinizing hormone in the eve. Endocrinology 141 1050-1058.

Huising MO, Kruiswijk CP \& Klik G 2006 Phylogeny and evolution of class-I helical cytokines. Journal of Endocrinology $\mathbf{1 8 9} \mathbf{1 . 2 5}$.

Kalra PS, Edwards TG, Xu B, Jain M \& Kalra SP 1998 The anti-gonadotropic effects of cylokines: the role of neuropeptides. Domestic Anumal Endocrinology $15321-332$.

Karsch FJ \& Battaglia DF 2002 Mechanisms for endot oxin-induced disruption of ovarian cyclicity: observations in sheep. Reproduction Supplement 59101. 113.

Maeda K \& Tsukamura H 2006 The impact of stress on reproduction: are glucocorticoids inhibitory or protective to gonadotropin secretion? Endocrinology 147 1085-1086.

Matsuwaki T, Watanabe E, Suzuki I, Yamanouchi K \& Nishikara M 2003 Glucocorticoid maintains pul satile secretion of luteinizing hormone under infec tious stress conditions. Endocrinology $1443477-3482$.
Matsuwaki T, Suzuki M, Yamanouchi K \& Nishikara M 2004 Glucocorlicoid counteracls the suppressive effects of tumour necrosis factor-a on the surge of luteinizing hormone in rats. Journal of Endocrinol. ogy 181 509-513.

Matsuwaki T, Kayasuga Y, Yamanouchi K \& Nishikara M 2006 Maintenance of gonadotropin secretion by glucocorticoids under stress conditions through the inhibition of prostaglandin synthesis in the brain Endocrinology 147 1087-1093.

Maya-Nunez G \& Conn PM 2003 Transcriptional regulation of the GNRH receptor gene by glucocorticoids. Molecular and Cellular Endocrinology 200 89-98.

Oakley AE, Breen KM, Tilbrook A], Wagenmaker ER \& Karsch FJ 2006 Differing modes of cortisol-induced suppression of pulsatile LH secretion in ovarieclomized ys, ovary-intact ewes, Biology of Reproduction, Special lssue for $39^{\text {th }}$ Annual Meeting of the Society for the Study of Reproduction 75 (abstract 19).

Perkowski SZ, Sloane PJ, Spath Jr JA, Elsasser TH, Fisher JK \& Gee MH 1996 TNF-a and the pathophysiology of endotoxin-induced acote respiratory failure in sheep. Journal of Applied Physiology $\mathbf{8 0}$ $564-573$.

Sapolsky RM, Romero IM \& Munck AU 2000 How do glucocorticoids influence stress responses? Integrating permissive, suppressive, stimulatory, and preparative actions. Endocrine Reviews 21 55-89.

Schillo KK, Alliston CW \& Malven PV 1990 Plasma concentrations of luteinizing hormone and prolactin in the ovariectomized ewe during induced hyperthermia. Biology of Reproduction 19 306-313.

Scammell TE, Elmquist JK \& Saper CB 1996 Inhibition of nitric oxide synthase produces hypothermia and depresses lipopolysaccharide fever. American lournal of Physiology 271 333-338.

Seminara SB, Messager S, Chatzidaki EE, Thresher RR, Acierno IS, Shagoury JK, Bo-Abbas Y, Kuohung W, Schwinof KM, Hendrick AG, Zahn D, Dixon J, Kaiser UB, Slaugenhaupt SA, Gusella JF, O'Rahilly S, Carlton MB, Crowley WF, Aparicio SA \& Colledge WH 2003 The GPR54 gene as a regulator of puberty. New England lournal of Medicine 3491614 1627.

Shepherd AJ, Downing JEG \& Miyan JA 2005 Without nerves, immunology remains incomplete - in verito veritas. Immunology 116 145-163.

Smith II, Cunningham MI, Rissman EF, Clifton DK \& Steiner RA 2005 Regulation of Kiss 1 gene expression in the brain of the female mouse. Endocrinology 146 3686-3692.

Stackpole CA, Turner AI, Clarke IJ, Lambert GW \& Tilbrook AJ 2003 Seasonal differences in the effect of isolation and restraint stress on the luteinizing hormone response to gonadotropin-releasing hormone in hypothalamopituitary disconnected, gonadectomized rams and ewes. Biology of Reproduction 69 1158-1164. 
Sternberg EM 1997 Neural-immune interactions in bealth and disease. Journal of Clinical Investigation $1002641-2647$.

Sternberg EM \& Webster II 2003 Neural immune inleractions in health and disease. In Fundamental immunology, edn 5, pp 1021-1042. Ed WE Paul. Philadelphia: Lippincott Williams and Wilkins.

Stevens DI 1995 Streplococcal toxic-shock syndrome: spectrum of disease, pathogenesis, and new concepts in treatment. Emerging Infectious Diseases 1 $69-78$.

Sugino T, Hasegawa $Y$, Kurose $Y$, Kojina $M$, Knagawa K \& Terashima Y 2004 Effects of ghrelin on food intake and neuroendocrine function in sheep. Animal Reproduction Science 82-83 183-194.

Tena-Sempere M 2005 Hypothalamic KiSS-1: the missing link in gonadoiropin feedback control. Endocrinology 146 3683-3685.

Turnbull AV \& Rivier CL 1999 Regulation of the hypothalamic-pituitary-adrenal axis by cytokines: actions and mechanism of action. Physiological Reviews 79 $1-71$.

Turrin NP \& Rivest S 2004 Unraveling the molecular details involved in the intimate link between the immune and neuroendocrine systems. Experimental Biology and Medicine 229 996-1006.
Tyree CM, Zou A \& Allegretto EA 2002 17B-Estradiol inhibits cytokine induction of the human E-selectin promoter. Journal of Steroid Biochemistry and Molecular Biology 80 291-297.

Vellucci SV \& Parrott RF 1996 Bacterial endotoxininduced gene expression in the choroid plexus and paraventricular and supraoplic hypothalamic nuclei of the sheep. Molecular Brain Research 43 41-50.

Wagenmaker ER, Breen KM, Clarke II, Oakley AE, Tilbrook AJ, Turner Al \& Karsch FJ 2005 Cortisol delays the estradiol-induced $\mathrm{LH}$ surge: is this dependent on prior ovarian steroid exposure? Biology of Reproduction, Special Issue for $38^{\text {th }}$ Annual Meeting of the Society for the Study of Reproduction 223 (abstract W645).

Williams CY, Harris TG, Battaglia DF, Viguié C \& Karsch FJ 2001 Endotoxin inhibits pituitary responsiveness to gonadotropin-releasing hormone. Endocrinology 142 1915-1922.

Wong M-L. Rettori V, Al-Shekhlee A, Bongiorno PB, Canteros G, McCann SM, Gold PW \& Licinio J 1996 Inducible nitric oxide synthase gene expression in the brain during systemic inflammation. Nature Medicine 2 581-584. 